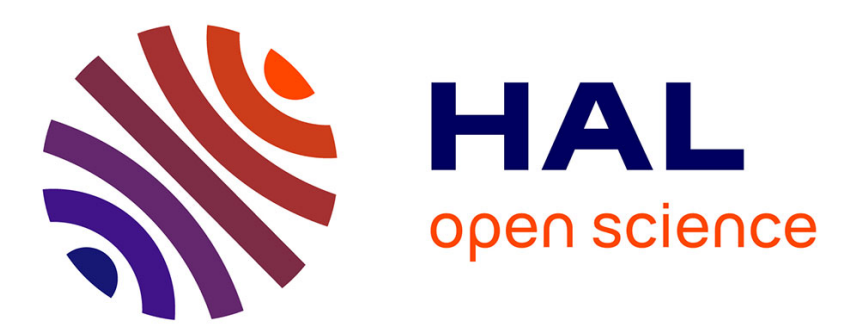

\title{
A chaperonin-like in the principal endocytobiotes of the weevil Sitophilus.
}

\author{
Hubert Charles, Abdelaziz Heddi, Paul Nardon
}

\section{To cite this version:}

Hubert Charles, Abdelaziz Heddi, Paul Nardon. A chaperonin-like in the principal endocytobiotes of the weevil Sitophilus.. Hainfried E.A. Schenk Reinhold G. Herrmann Kwang W. Jeon Norbert E. Müller Werner Schwemmler. Eukaryotism and Symbiosis: intertaxonic combination versus symbiotic adaptation, Springer, pp.395-402, 1997, 978-3-540-63375-4. hal-03505990

\section{HAL Id: hal-03505990 \\ https://hal.inrae.fr/hal-03505990}

Submitted on 4 Jan 2022

HAL is a multi-disciplinary open access archive for the deposit and dissemination of scientific research documents, whether they are published or not. The documents may come from teaching and research institutions in France or abroad, or from public or private research centers.
L'archive ouverte pluridisciplinaire HAL, est destinée au dépôt et à la diffusion de documents scientifiques de niveau recherche, publiés ou non, émanant des établissements d'enseignement et de recherche français ou étrangers, des laboratoires publics ou privés. 
H.E. A. Schenk - R. G. Herrmann - K. W. Jeon N.E. Müller $\cdot$ W. Schwemmler (Eds.)

\section{Eukaryotism and Symbiosis}

Intertaxonic Combination versus Symbiotic Adaptation

With 145 Figures

Springer-Verlag Berlin Heidel bay

$$
1997
$$


nschädigender Homopteren und de, Dissertation, Halle (Saale)

3 Philips University Uji-Kyoto ion. Paul Parey, Berlin

\section{A Chaperonin-Like in the Principal Endocytobiotes of the Weevil Sitophilus}

\author{
H. Charles, A. Heddi and P. Nardon \\ Laboratoire de Biologie Appliquée INSA-406, UA-INRA 203, SDI-CNRS 5128, 20 Ave- \\ nue A. Einstein, 69621 Villeurbanne Cedex, France
}

Key words: chaperonin, endocytobiosis, symbiosis, Sitophilus, weevil.

Summary: Chaperonins are ubiquitous proteins found in all prokaryotic and eukaryotic cells. They are expressed at high level in several parasitic bacteria and in at least two types of endocytobiosis: in amoebae and in aphids.

In this study, we have investigated the presence of a chaperonin-like, named symbionin, in the principal endocytobiotes of the weevil Sitophilus. This protein of $60 \mathrm{kDa}(\mathrm{pHi}=6.1)$ shares a high immunological homology with the groEL chaperonin of $E$. coli and is present in the three symbiotic species of Sitophilus $(S$. oryzae, $S$. granarius and $S$. zeamais). In isolated endocytobiotes, the symbionin represents $40 \%$ in quantity of the total expressed proteins. These results show the important role of symbionin in the maintenance of the symbiocosme.

\section{Introduction}

Chaperonins are ubiquitous proteins which ensure that the folding of polypeptides and their assembly into oligomeric structure occur correctly (Hendrick and Hartl 1993). They are often described in parasitic bacteria because of their high immunogenecity (Shinnick 1991). However, the biochemical function of the chaperonins during the invasion of the host by the bacteria is not known. Considering that endocytobiotes could have evolved from parasitic bacteria (Paillot 1933), it is very interesting to know whether symbiotic organisms still express such a protein or not. It must be pointed out that a chaperonin is expressed at high level in some of the oldest known descendants of endocytobiotes such as mitochondria and chloroplasts (Hemmingsen et al. 1988; Gupta et al. 1989).

In the case of endocytobiosis, a chaperonin-like protein has already been described in two models: the pea aphid Acyrthosiphon pisum (Ishikawa 1984) and the amoebae Amoebae proteus (Jeon 1983). In these two models, the genes encoding the chaperonin are located downstream of an $E$. coli groES-like gene. Both genes (symL and groEx) are heat shock regulated (Ohtaka et al. 1992; Ahn et al. 1994). 


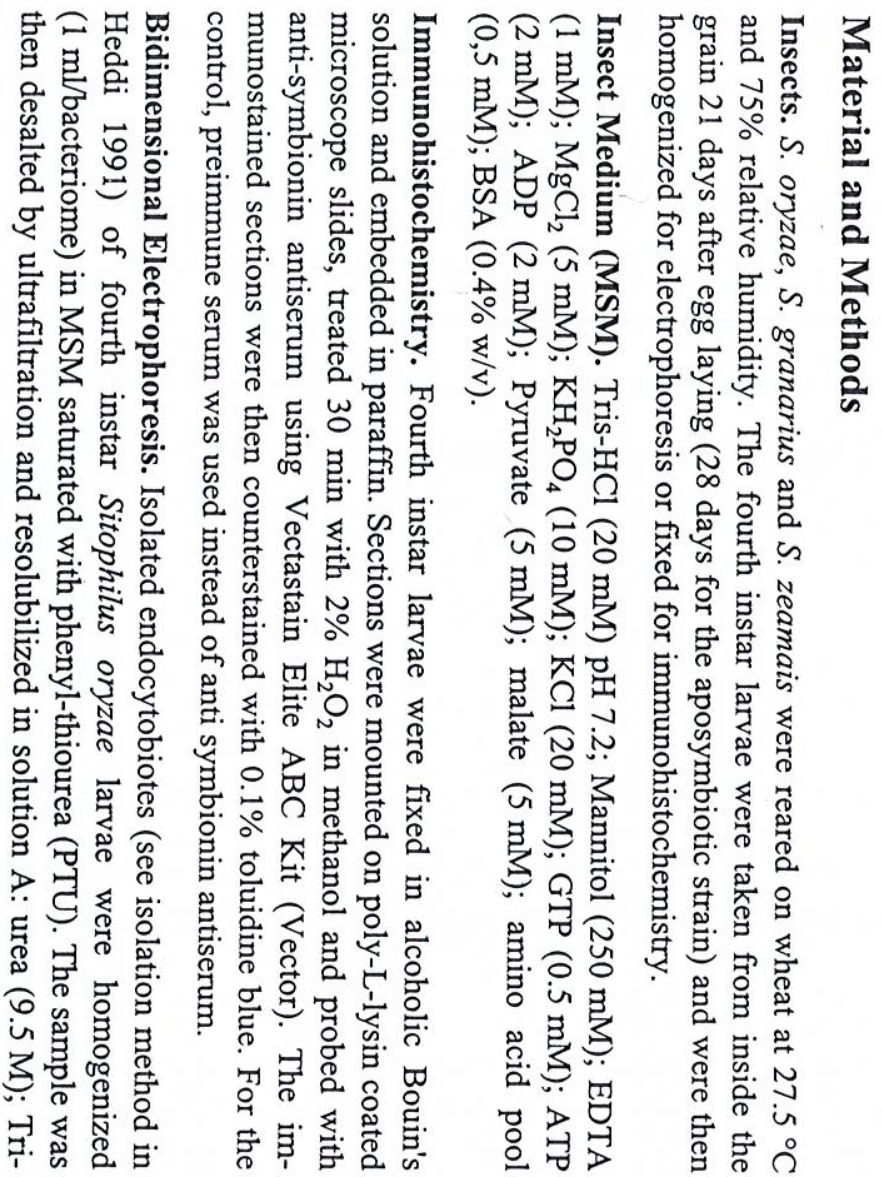

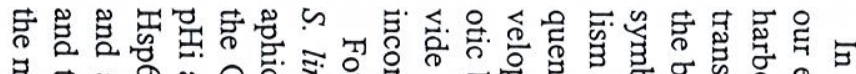

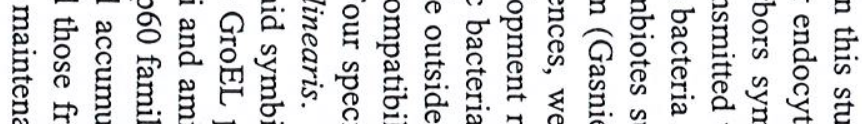

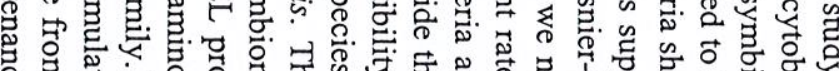

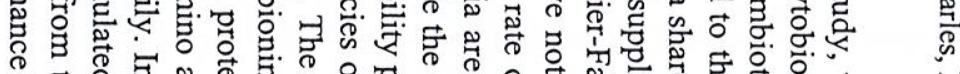

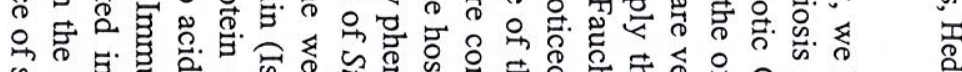

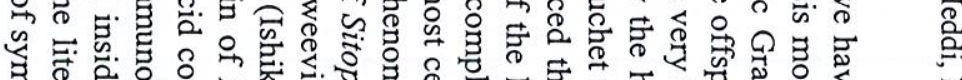

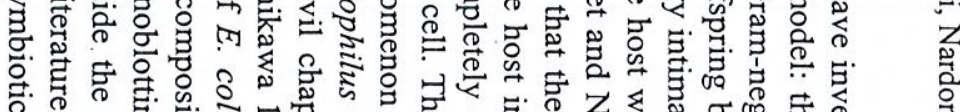
万人

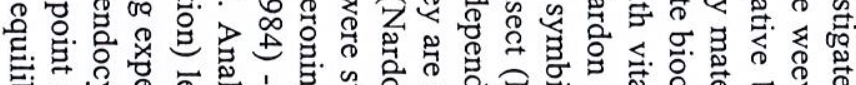

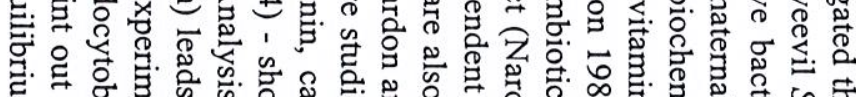

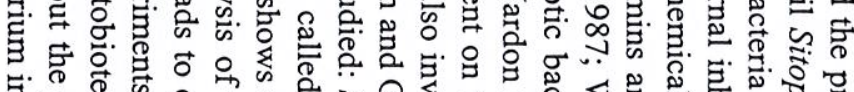

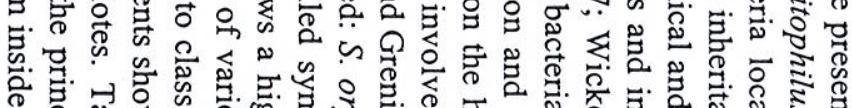

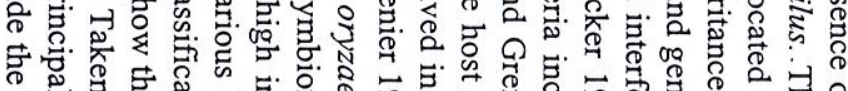

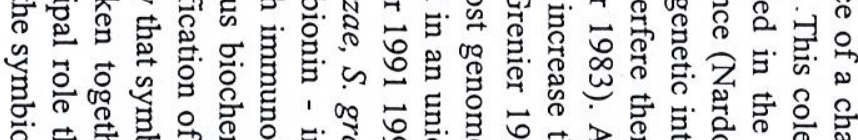

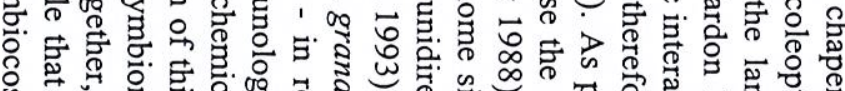

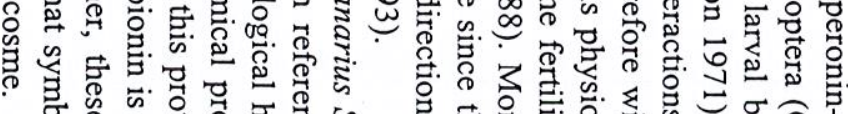

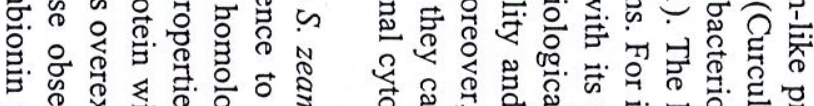

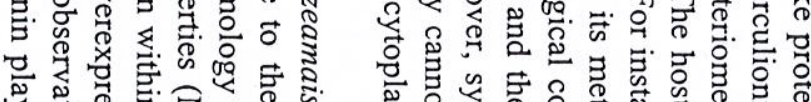

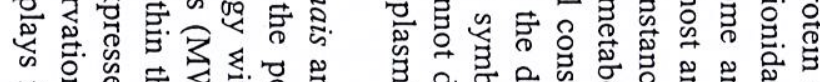

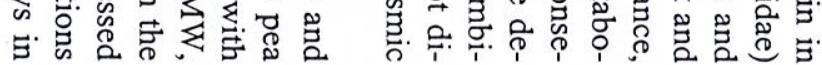

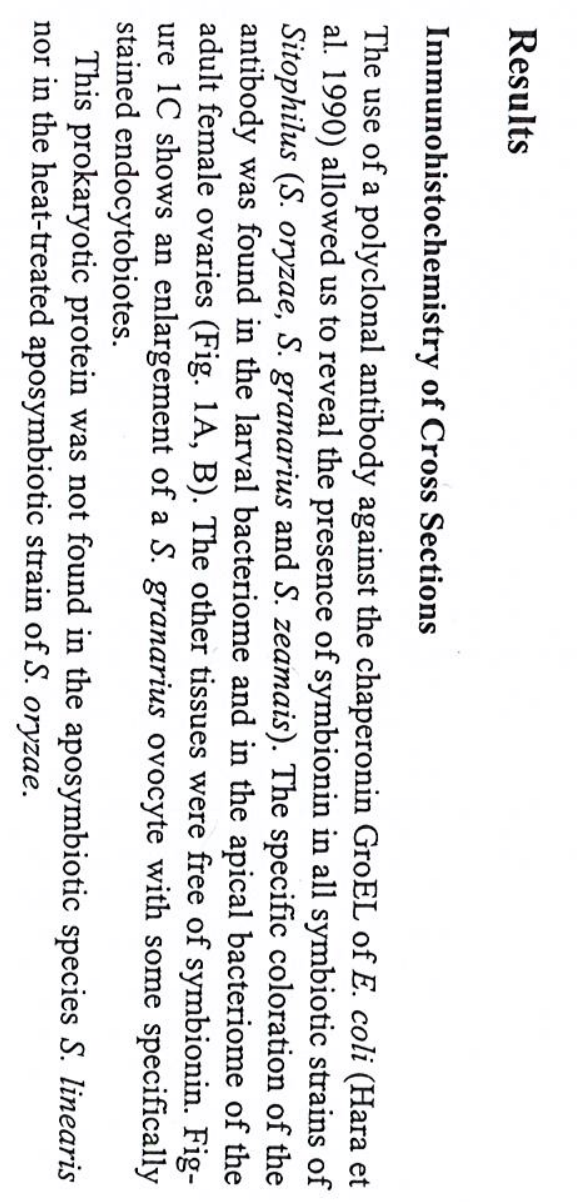

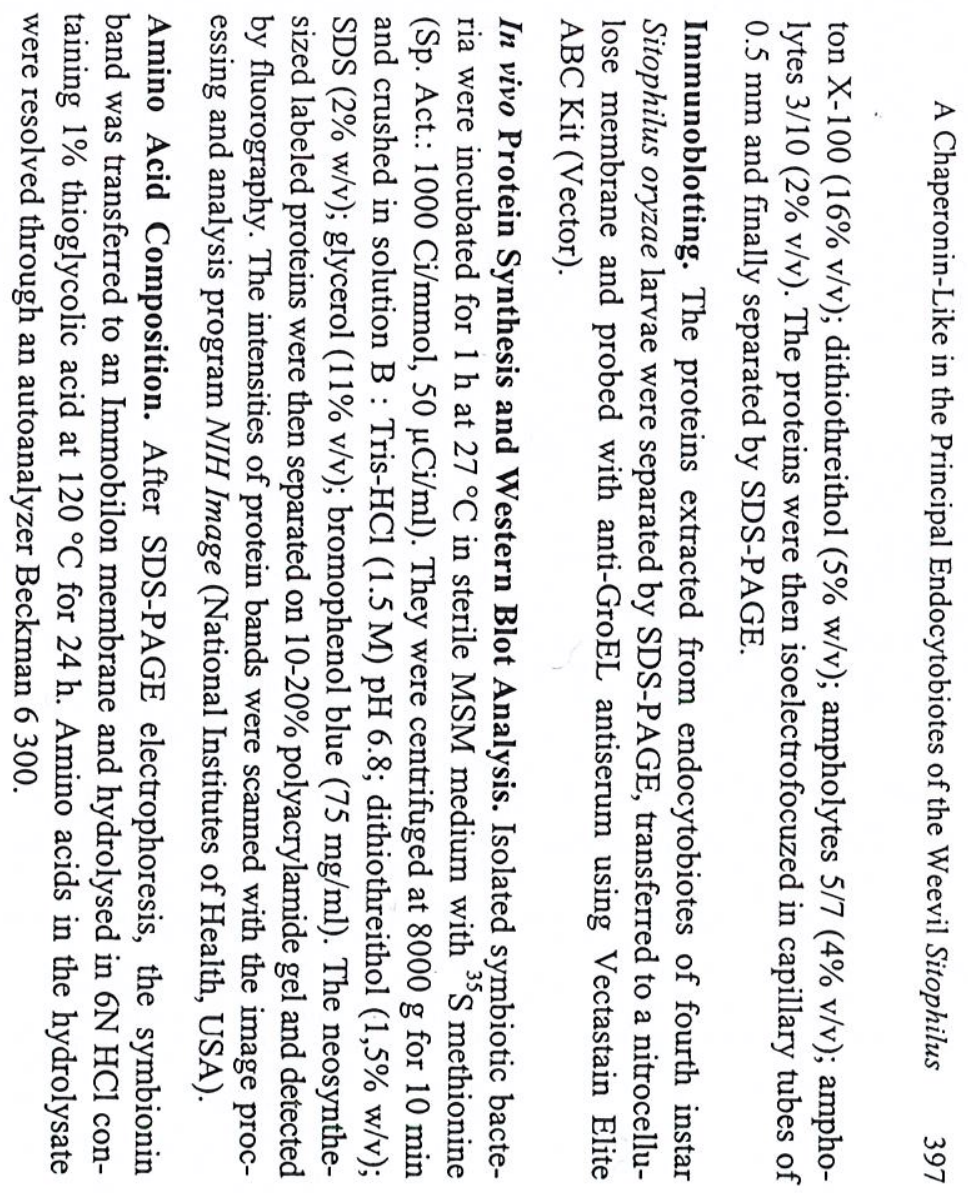



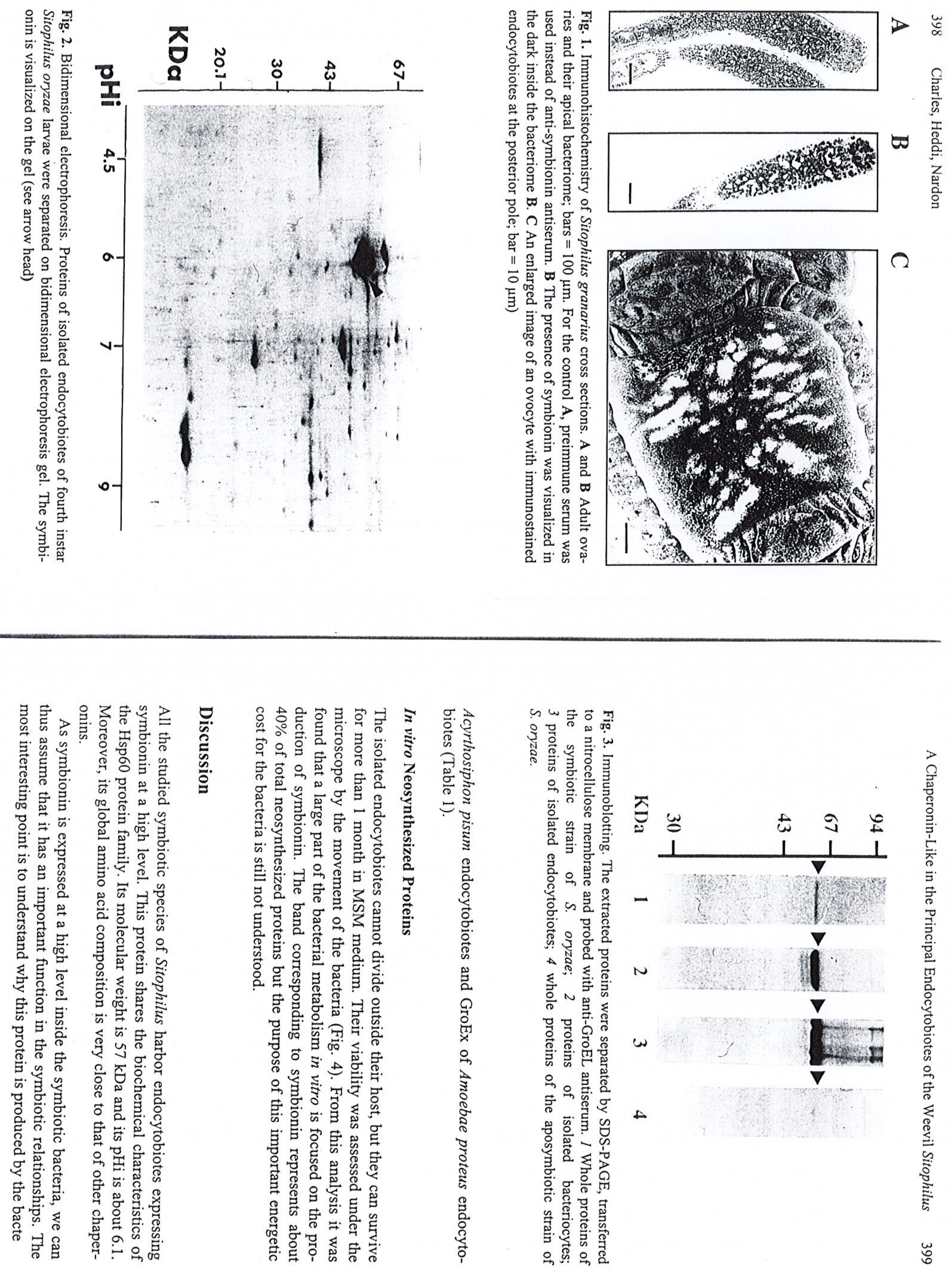


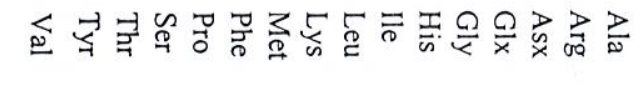

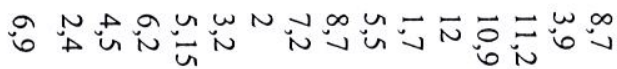

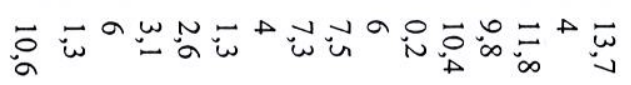

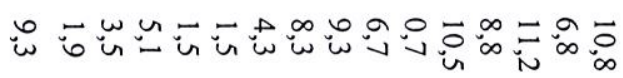

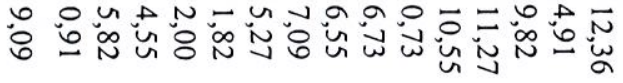

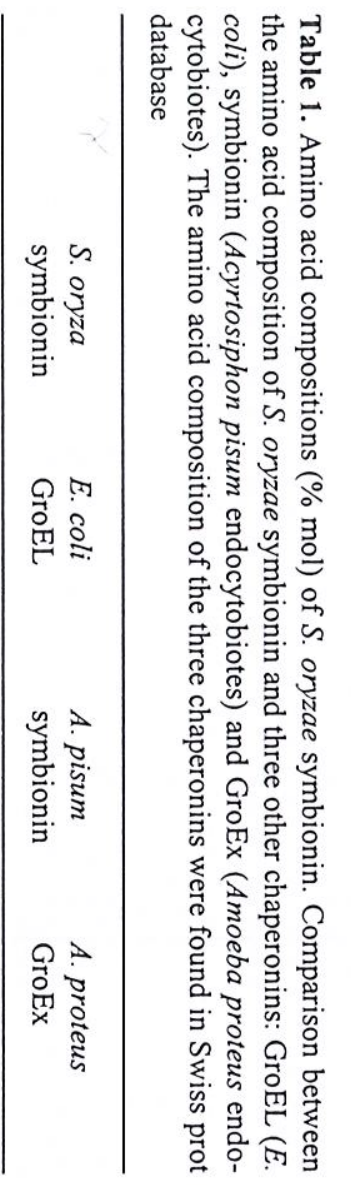

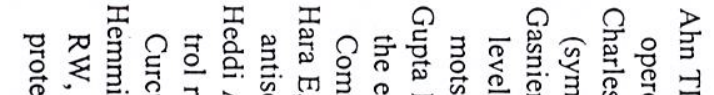

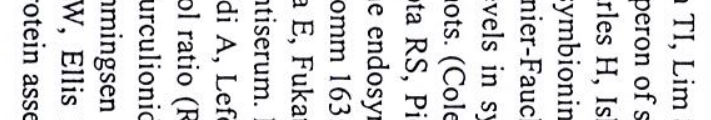

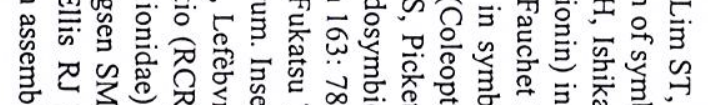

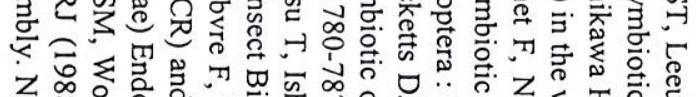

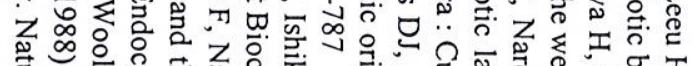

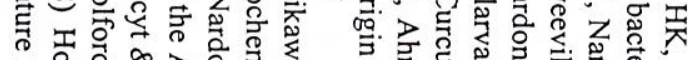

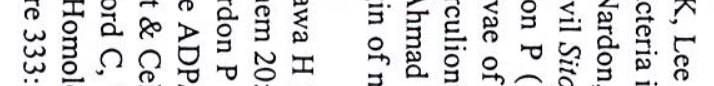

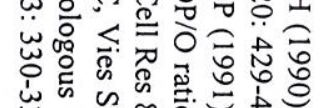

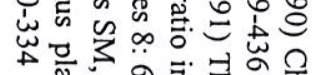

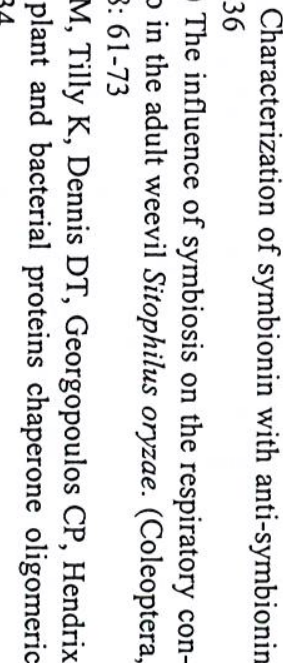

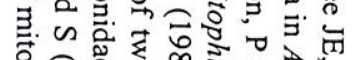

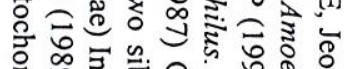

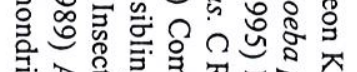

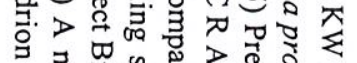

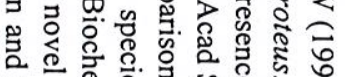

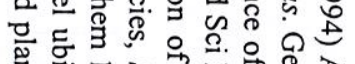

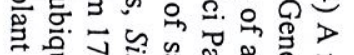

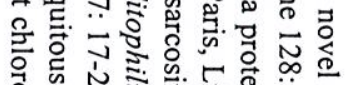

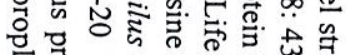

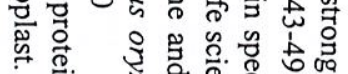

प्र.

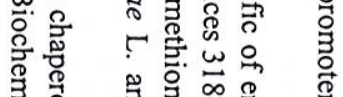

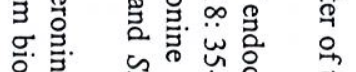

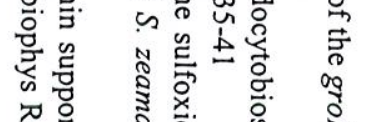

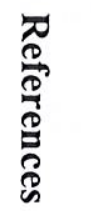

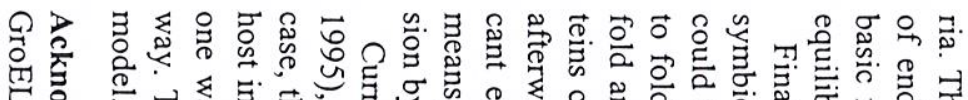

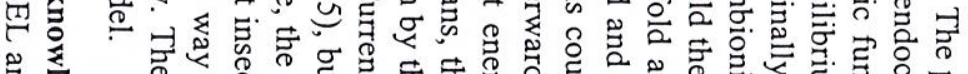

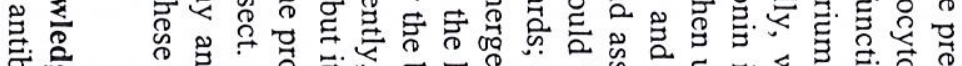

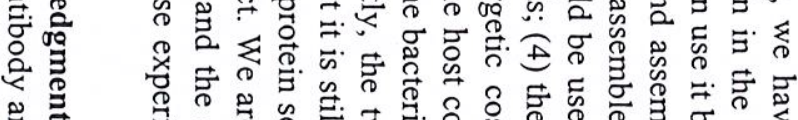

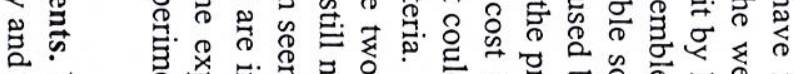

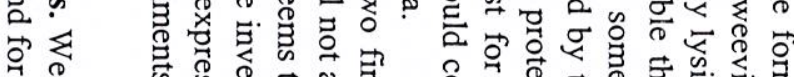

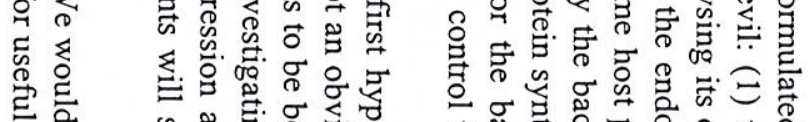

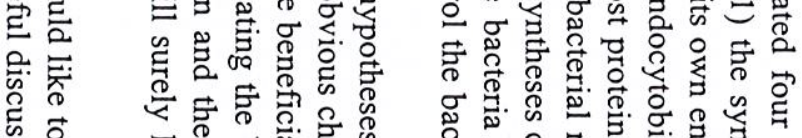

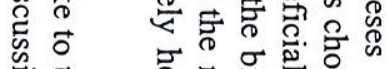

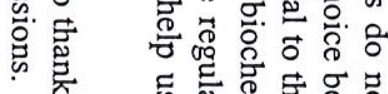

ह क

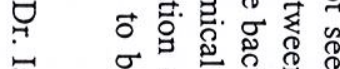

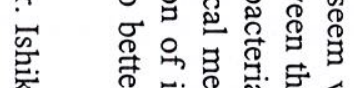

ก

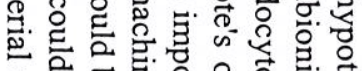

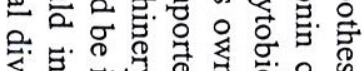

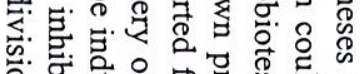

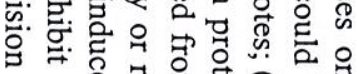

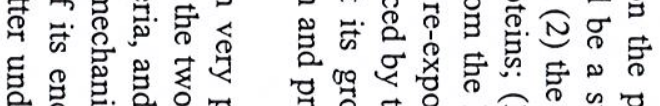

预

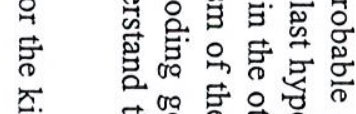

좀.

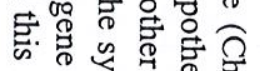

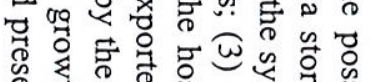

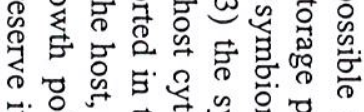

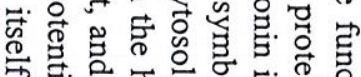

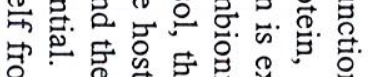

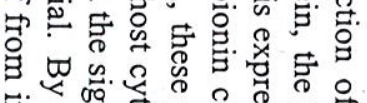

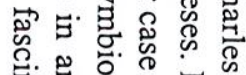

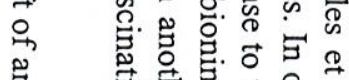

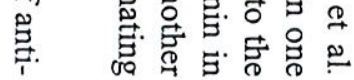

范

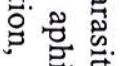

E.

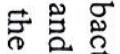

密

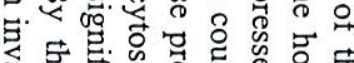

을. 起要
के के ते

$\cdot$

$\forall$ क

总芯芯芯

串迅

กิ๊

윻

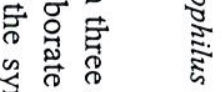


Z8I-LLI : $\forall 9 L$ loIs

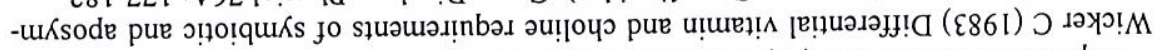
09 I-

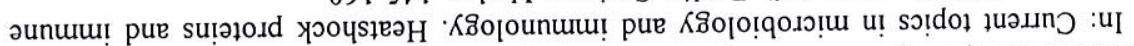

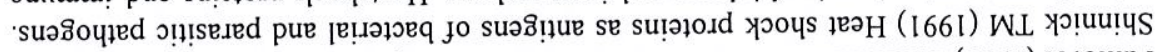

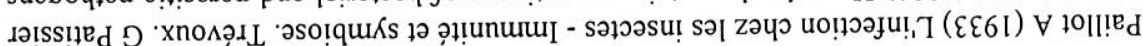
$\nabla \angle 8 \mathrm{I}-698 \mathrm{I}: \nabla \angle \mathrm{I}$

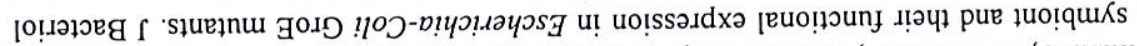

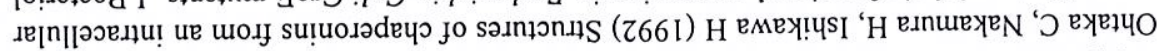
Ot I

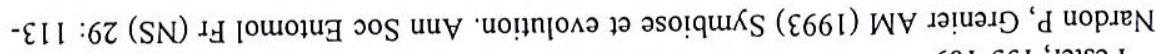
69 I-عs I 'دә15ว

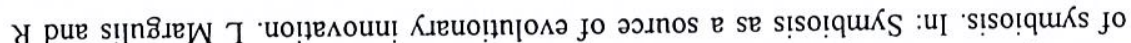

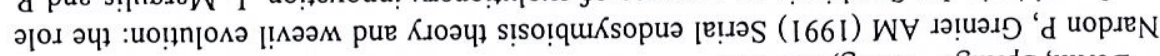

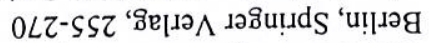

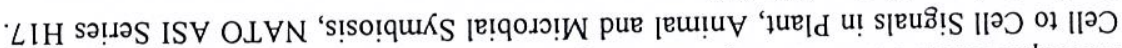

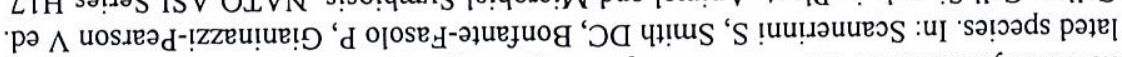

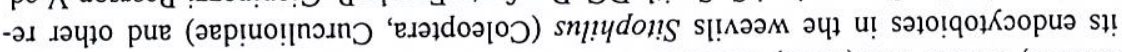

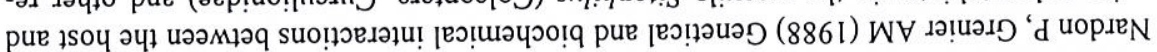

$8 \angle 6 Z-\varsigma L 6 Z: G Z L Z$

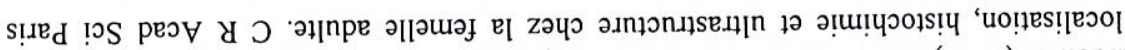

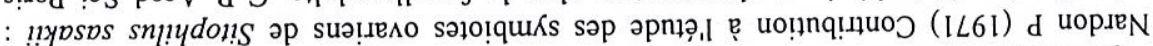
$\angle \nabla-6 Z: t$ I मиәшәd

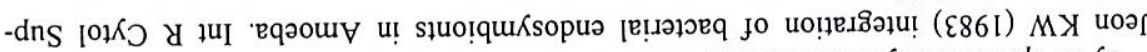

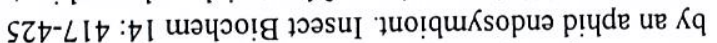

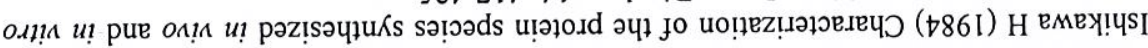

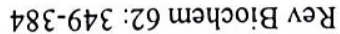

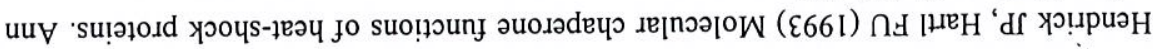

